\title{
DANAŠNJE STANJE SLOVENSKE MUZIKOLOGIJE
}

\section{Dragotin Cvetko (Ljubljana)}

Kar je bilo na Slovenskem pred drugo vojno na področju muzikologije, še ni bilo načrtno in tudi ne obsežno. Tedaj se ta disciplina še ni uspela uvrstiti ne med slovenske znanosti in tudi ne med študijske smeri na filozofski fakulteti ljubljanske univerze. ${ }^{1}$ Strokovnjaki se zanjo zato doma še niso mogli formirati, kolikor so se izšolali v tujini, pa na Slovenskem niso imeli možnosti, da bi se ustrezno zaposlili in obenem posvetili intenzivnemu raziskovalnemu delu. Le-to je bilo omejeno na redke poedince in tudi tem je največkrat pomenilo samo sekundarno dejavnosth. Še Josip Mantuani, ki je $\mathrm{v}$ Času svojega dunajskega bivanja dal muzikologiji z biografskim orisom J. Gallusa (DTÖ VI, 1, 1899), s sodelovanjem v izdaji Opus musicum tega skladatelja, z Geschichte der Musik in Wien I (1904) in vrsto nadaljnjih razprav vredne prispevke, ${ }^{2}$ svojega muzikološkega dela ni več nadaljeval na enak način potem, ko se je po prvi vojnt vrnil v Ljubljano. Sicer je še marsikaj napisal, kar se je nanašalo na preteklost slovenske glasbe, vendar večidel nedokumentirano. Nadarjeno razmišljujočega Stanka Vurnika, ${ }^{3}$ ki je obenem preučeval nekatera vpraŠanja s področja slovenske etnologije, je zlasti zanimal stil v glasbi, o katerem je razpravljal $\mathrm{v}$ svojem Uvodu $\mathrm{v}$ glasbo (1929). Njegovo delo je veljalo tudi slovenski glasbeni folklori, ki pa se je kot raziskovalna smer najbolj koncentrirala $\mathrm{v}$ načrtno zastavljenih prizadevanjih Franceta Marolta..$^{4}$

Kolikor so bila, so se torej slovenska muzikološka razpravljanja med obema vojnama odvijala $\mathrm{v}$ treh smereh. Največ jih je bilo na podrocjus glasbenega zgodovinopisja, za katero se kažejo prvi začetki in tudi določeni rezultati že proti koncu 19. in neposredno po vstopu v 20 stoletje. V tej zvezi je treba spomniti pisce kot so bili npr. Fran Rakuša, ${ }^{5}$ Anton

\footnotetext{
${ }^{1}$ Gl. zbornik Petdeset let slovenske univerze $v$ Ljubljani, 1969, 279, 280.

${ }^{2}$ Musik in Geschichte und Gegenwart (MGG) 8, 1605-1606; Muzička enciklopedija (ME) 2, 1974, 526.

${ }^{3}$ MGG 14, 49; ME 2, 1963, 788.

4 MGG 8, 1665-1666; ME 2, 1974, 534-535.

${ }^{3} \mathrm{ME}$ 2, 1963, 461. - Rakuševo Slovensko petje $v$ preteklih dobah (1890) jo bilo prvi oris slovenske glasbe preteklosti; ceravno to delo še ni bilo sistematicno zasnovano, ima vendar nek razvojni pomen.
} 
Trstenjak, 6 Viktor Steska, Davorin Beranic, ${ }^{8}$ pa še Peter Radics ${ }^{9}$ in Friedrich Keesbacher, ${ }^{10} \mathrm{ki}$ sta $\mathrm{v}$ slovensko glasbeno zgodovinopisje prispevala vsaj posredno. Tudi v času med prvo in drugo vojno so bila prizadevanja skromna. Na področju zgodovinopisja so se Mantuaniju in Steskị v širšem smislu priključili še nekateri sodelavci, tako Anton Dolinar,11 Vilko Ukmar' ${ }^{12}$ in Lucijan Marija Škerjanc,13 a le občasno in samo delno. V primerjavi s tem področjem je bila glaşena folkloristika načrtnejša in uspešnejša. O tem povedo objavljena dela, pa tudi Folklorni institut, ki ga je $\mathrm{v}$ okviru Glasbene matice ljubljanske $v$ letu 1934 osnoval F. Marolt.14 Orientacija v stilno-estetska razmišljanja in iskanja je bila osamljen pojav, po Vurniku $\nabla$ tej smeri ni bilo konkretnega nadaljevanja.

Glasbena publicistika in kritika sta bili v navedenem casu precej razr vejani. To je mogoče pojasniti z razraščanjem slovenskega glasbenega ustvarjanja, ki se je $\mathrm{v}$ dvajsetih letih in še posebno $\mathrm{v}$ tridesetih letih začelo Širiti v evropski okvir, v katerem je želelo čimprej postati enakovreden razvojni dejavnik.

V primerjavi z ravnokar opisano situacijo kaže slovenska muzikologija po drugi vojni znatno drugačno podobo. Uveljavilo se je spoznanje, da sodi ta disciplina med temeljne nacionalne znanosti in je zato potrebna. Da bi zaživela, je potrebovala strokovne in znanstvene delavce. Formiranje le-teh je bilo $\mathrm{v}$ prvi fazi (1945-1962) $\mathrm{v}$ okviru ljubljanske Akademije za glasbo, ${ }^{15}$ potem pa na ljubljánski univerzi, kjer je bil s sklepom univerzitetnega sveta (1961) osnovan in na njeni Filozofski fakulteti realiziran (1962) oddelek za muzikologijo. ${ }^{16} \mathrm{~V}$ tej instituciji je bila zagotovljena tudi

- V njegovi knjigi Slovensko gledališče (1892) so bili podatki o zacetkih slovenske glasbenoodrske reprodukcije, $\mathrm{ki}$ jih je treba upoštevati zlasti $\mathrm{v}$ primerih, ko izvirno gradivo manjka.

7 Prispevke, ki se deloma ali v celoti nanašajo na zgodovino slovenske glasbe, je najprej objavil $\mathrm{v}$ Domu in svetu XV (1902), Izvestjih Muzejskega drustva za Kranjsko X (1900) in XV (1905) ter Cerkvenem glasbeniku (CG) XXXV (1912), $\checkmark$ tridesetih letih pa $v$ Mladiki XVI (1935) in CG LV (1932), LVIII (1935) in IXIII (1940).

- Iz raziskovanja slovenske glasbe je dal sicer drobne, a tehtne prispevke. Gl. Slovenski biografski leksikon (SBL) 1,33 .

- Med njegovimi objavami, ki so večidel splošne zgodovinske narave in $\mathrm{v}$ nemskem jeziku, so tudi take, ki se neposredno ali posredno ticejo slovenske glasbe ali glasbenega dela na Slovenskem, npr. Frau Musica in Krain (1877). K temu şe gl. gradivo v Narodni in univerzitetni knjižnici v Ljubljani (NUK), glasbena zbirka, in SBL 9, $4-7$.

10 SBL 3, 440-441; gradivo v NUK, glasb. zbirka.

1 SBL 1, 141; CG IXXII, 1940.

$12 \mathrm{ME} \mathrm{2,1963,741.}$

33 Izpred druge vojne je njegova knjiga o Emilu Adamicu (1938). Gl. ME 2, 1963, 675 in MGG 12, 748-749.

${ }_{14}$ Po drugi vojni se je preosnoval v Glasbeno-narodopisni institut in osamosvojil; zdaj je sekcija za glasbeno narodopisje Etnografskega instituta Slovenske akademije znanosti in umetnosti (SAZU). Glede na to, da se etnomuzikologija na splošno tretira kot samostojno področje izven muzikologije, njegovo delo tu nı zajeto, ravno tako tu niso navedeni rezultati znanstvenih raziskav, ki so po drugi rojni nastali $v$ tej smeri.

${ }^{15}$ Gl. cit. zbornik Petdeset let slovenske univerze $v$ Ljubljani, 280.

16 Podrobnejše gl. ibid., 280-282. 
realna možnost za izdelovanje magistrskih del in doktorskih disertacij, ki je doslej ni bilo, poslej pa predstavlja za intenzivno usmerjanje $\mathrm{v}$ raziskovalno dejavnost pomemben faktor.

Načrtnost, ki je spremljala sedanja prizadevanja, je spodbudila tudi potrebo za muzikološko periodiko, $\mathrm{v}$ kateri bi mladi in mlajši muzikologi objavljali dosežke svojega dela, razprave manjšega obsega. Dotedanji slovenski glasbeni tisk ${ }^{17}$ po tej strani ni nudil, kar bi bilo treba, bolj kot glasbeni znanosti je bil namenjen glasbeni publicistiki. Z Muzikološkim zbornikom ${ }^{18}$ pa se je to stanje spremenilo. $V$ uvodni besedi njegovega prvega zvezka je bilo rečeno, da je in bo njegov namen wobjavljanje znanstvenih prispevkov vseh in predvsem mladih slovenskih muzikologov", a tudi "muzikologov drugih narodnosti na področju naše države in izven nje, kolikor bodo njihovi prispevki sodelovali v realizaciji njegovih ciljev«.19 Idejni in delovni koncept je bil dan in usklajen s tem, kar so $\mathrm{v}$ širokem razponu zahtevale naloge slovenske muzikologije.

Med spodbude, ki so se pojavile $\mathrm{v}$ tej smeri in so še stopnjevale aktivnost znanstvenih prizadevanj, je treba še marsikaj šteti, tako npr. aktualnost habilitacijskih del, postopno večanje možnosti za objavljanje publikacij izven načrtovanih programov in širjenje delokroga $\mathrm{v}$ domacem ter mednarodnem prostoru. $\mathrm{K}$ temu so posredno ali neposredno prispevali razni faktorji, med njimi npr. $\mathrm{X}$. kongres Mednarodnega muzikoloskega društva (International Musicological Society-IMS) v letu 196720 in tematično zanimiv simpozij v letu 1971,21 oba v Ljubljani.

Muzikološka prizadevanja, ki so na Slovenskem znana za cas po drugi vojni, so bila neposredno odvisna od vprašanja, katerim za teorijo in prakso pomembnim izhodiščem gre $\mathrm{v}$ danih razmerah in potrebah prvenstvena veljava.

Orientacija znanstvenega pristopa $v$ tej zvezi ni bila najbolj obcutljiv problem. Po tej strani je bilo treba uveljaviti metodologijo sodobne mizikologije nasploh in $\mathrm{v}$ posameznostih $\mathrm{s}$ poudarkom na bistvu umetnine ter $\mathrm{s}$ potrebo izhajanja iz njene strukture, $\mathrm{s}$ tem pa $\mathrm{z}$ novim pojmovanjem

${ }_{17}$ Vanj se po drugi vojni uvrščajo Naši zbori, katerih prva številka je izsla 1946, nadalje Slovenska glasbena revija, ki jo je 1951 začelo izdajati Društvo slovenskih skladateljev (DSS), in mladinska glasbena revija Grlica (od 1953), s katero se je nadaljevalo to, kar je začela revija $s$ tem imenom že prej v letih 19331935. Vsem tem revijam je bilo skupno to, da so želele objavljati izvirne kompozicije manjših form (vokalne, klavirske), kar pa je bilo cedalje manj potrebno, saj so se možnosti izdajanja takih skladb zdaj občutno zvečale. Cit. revije só imele tudi literarne priloge po zgledu prejšnjih vrstnic (Novi akordi, Nova muzika, Zbori). Po tej strani jih je zanimala predvsem glasbena publicistika, kar velja, ceravno v omejenem smislu, tudi za Koncertni list, ki ga je 1951 začela izdajati Slovenska filharmonija $\mathrm{v}$ Ljubljani.

18 Izhajati je začel 1965, poslej izhaja letno po en njegov zvezek.

19 Muzikološki zbornik (MZ) I, 1965, 6.

${ }_{20}$ Bistveni delež $\mathrm{v}$ pripravljanju in izvedbi tega kongresa je dal oddelek za muzikologijo ljubljanske Filozofske fakultete, ki je sodeloval tudi $\mathrm{v}$ realizaciji poroxila o njem (gl. IMS Report of the Tenth Congress Ljubljana 1967, Kassel-Ba. sel-Paris-London-Ljubljana 1970).

${ }^{21}$ Gl. MZ VIII, 1972, 5-16. - Na tem simpoziju so bila obravnavana vprašanja muzikalne tradicije, umetnine, citata in analize. 
usklajen analitični proces, ki zahteva sodobno metodološko in tehnološko verziranost; ob tem so seveda bili $\mathrm{v}$ interpretativnih in sklepnih konsekvencah pomembni tudi za bistvo obravnavanega fenomena važni aspekti, ki lahko pojasnijo vzroke njegova nastoja, njegovo zasnovo in posledično pomembnost.

Važnejše kot to, kar za realizacijo sploh ni bilo problem, celo najvažnejše je bilo vprašanje, kam, v katero področje bo v trenutku, ko se je glasbena znanost $\mathrm{v}$ mednarodnem prostoru že široko specificirala in v svojem okviru razvila vrsto samostojnih disciplin, najprej krenila slovenska muzikologija. Odločila se je za historično smer, se pravi za zgodovino glasbe, $\mathrm{ki}$ je nasploh tudi drugod še vedno osrednja disciplina, zdaj uprta $\mathrm{v}$ nova spoznanja o sistematiki raziskovanja in obravnavanja tematičnega gradiva. Temu je dala prvenstvo. Bolj kot splošni22 je namenila zanimanje zgodovini slovenske glasbe, da bi le-ta bila "dostopna spoznavanju na domačih tleh" in bi bila tudi možnost, da postane isestavni del zgodovine svetovne glasbe,$^{23}$ kar se doslej še ni zgodilo, ker je preprosto ni bilo.

$\mathrm{V}$ tej smeri so bile raziskave in preučevanja najbolj intenzivna za starejša razvojna obdobja, vanje so poleg starejših prispevali tudi stevilni mlajši muzikologi, ki so nastopili po drugi vojni. Ob literaturi, 23a ki ja obravnavala glasbeno preteklost na slovenskih tleh $\mathrm{v}$ celoti, ${ }^{24}$ je še nastala vrsta drugih orisov, ki so tematično različno zastavljeni. Zajemajo širše ${ }^{25}$ ali ožje izseke iz pretekle slovenske glasbe ${ }^{26}$ ali specifične snovi v okviru, ki se časovno veže na eno ali lahko seže na več tematično aktualnih razvojnih razdobij. ${ }^{27}$

22 V tej smeri je 1948 izšla Zgodovina glasbe (V. Ukmar - D. Cvetko-R. Hrovatin), 1957 Glasba $v$ preteklih dobah V. Ukmarja in 1972 Glasba preteklosti istega avtorja. S podrőja Širše tematike je še Opera skozi stoletja J. Sivca (1976) ta tema je v širšem smislu zanimala že prej (gl. M. Kozina, Svet operne glasbe, 1962; C. Cvetko, Opera in njeni mojstri, 1963) - in tudi Musikgeschichte der Südslawen (1975) D. Cvetka. Izvenslovenske teme so bili redkeje predmet obravnavanja slovenskih muzikologov. Mednje spada npr. razprava J. Sivca o realizaciji teksta Ecce, quomodo moritur justus $v$ kompozicijah J. Gallusa, M. A. Ingegnerija in O. di Lassa (MZ, VII) in sestavek J. Höflerja o D. Phinotu in začetkih renesančnega večzborja (Zvuk, 1970); slednji je izdal (doslej) tudi I. in II. zv. v okviru izdaje opusa D. Phinota, razen tega en Miserere J. B. Dolarja.

${ }^{23} \mathrm{MZ}$ I, $1965,6$.

${ }^{23 a} \mathrm{~K}$ temu prim. tudi Cvetko D., Les formes et les résultats des efforts musicologiques yougoslaves, Acta musicologica XXXI, 50-62.

${ }^{24}$ Cvetko D., Zgodovina glasbene umetnosti na Slovenskem, I-III (1958-1960); 1sti, Stoletja slovenske glasbe (1964); isti, Histoire de la musique slovène (1967).

${ }^{25}$ Höfler J., Tokovi glasbene kulture na Slovenskem od začetkov do 19. stoletja (1970).

${ }^{26}$ Rijavec A., Glasbeno delo na Slovenskem $v$ obdobju protestantizma (dis., 1967); Cvetko D., Odmevi glasbene klasike na Slovenskem (1955).

${ }^{27}$ Sivec J., Opera $v$ Stanovskem gledališču $v$ Ljubljani od leta 1790 do leta 1861 (dis., 1971); Kuret P., Glasbeni instrumenti na srednjeveških freskah na Slovenskem (dis., 1973); Höfler J., Slovenska cerkvena pesem $v$ 18. stoletju - Tipološkł prikaz njenega glasbenega stavka (dis., 1975); Spendal M., Glasbene predstave na odru mariborskega gledališča od 1785 do 1861, (mag. delo, 1975); Cvetko D., Academia Philharmonicorum Labacensis (1962); isti, Vloga Gojmira Kreka $v$ razvoju novejše slovenske glasbe (1977). - Glede na specifičnost tematike 
Te in one vrste orisi temeljijo na stanju, ki je bilo glede na vire $\mathrm{v}$ času in prostoru, ko in kjer so nastali. $\mathrm{V}$ nadaljevanju raziskav se bodo seveda izpopolnjevali in bodo podvrženi reviziji, če jo bo zahtevalo novo, prej še neznano gradivo. Iz rezultatov je razviden tudi idejni koncept, značilen za tega ali onega raziskovalca, ki je sodeloval $\mathrm{v}$ osvetljevanju problematike in faktov.

$\mathrm{V}$ načelu in praksi velja vse to, čeravno ne morda $\mathrm{z}$ enako razsežnostjo in istimi posledicami, tudi za vse druge prispevke, ki so nastali $\mathrm{v}$ povojnih prizadevanjih in obravnavajo razne teme iz zgodovine starejše slovenske glasbe. Mednje spadajo monografije o nekaterih slovenskih skladateljih, ${ }^{28}$ številne razprave, ki so bile objavljene doma ${ }^{29}$ ali na tujem ${ }^{30}$ $\mathrm{v}$ muzikološkem in splošnem glasbenem tisku in so njihovi avtorji razen slovenskih še nekateri tuji strokovnjaki, 31 pa tudi izdaje kompozicij iz slovenske preteklosti. ${ }^{32}$

smemo sem uvrstiti še dve publikaciji, ki analitično segata $\mathrm{v}$ bistvena vprašanja nekega kompozicijskega stavka: Kompozicijska tehnika Jakoba Petelina-Gallusa (1963) L. M. Škerjanca in Kompozicijski stavek Wolfganga Stricciusa (habil. delo, 1972) J. Sivca. Ta in ona obsegata tudi temeljne biografske podatke, ki so za oba navedena skladatelja sicer pomanjkljivi, še zlasti za zadnjega, $v$ obeh pa je težišče na značilnostih kompozicij in iz njih izhajajočih sklepov. Poudarjen analitični pristop $\mathrm{k}$ strukturi kompozicijskega stavka je aktualen tudi za raziskave, ki so ravnokar aktualne in jih zanimata opusa Daniela Lagkhnerja (Sivec J., Zbirka Florum Jessaeorum... Daniela Lagkhnerja, MZ XII) in Amandusa Ivančiča (D. Pokorn, dis., predložena in 1977 obranjena na Filozofski fakulteti v Ljubljani).

${ }^{28}$ Samostojne so izśle naslednje publikacije: Škerjanc L. M., Jurij Mihavec slovenski skladatelj in pianist (1957); isti, Anton Lajovic (1959); Cvetko D., Jacobus Gallus Carniolus (1965); isti, Jacobus Gallus - Sein Leben und Werk (1972); isti, Davorin Jenko i njegovo doba (1952); isti, Davorin Jenko, Doba-Življenje-Delo (1955); isti, Risto Savin - Osebnost in delo (1949); isti, Život i rad kompozitora Rista Savina (1958); Turel M., Skladatelj Miroslav Vilhar (1963). - V gradivo za osvetljevanje osebnosti slovenske glasbe sodi tudi prispevek V. Ukmarja z naslovom Srečanja z Julijem Betettom (1961).

${ }^{29}$ Teh razprav je prerej; v pričujočem sestavku so omenjene le nekatere, izcrpneje so navedene $\mathrm{v}$ leksikalni oz. enciklopedični literaturi (ME, MGG in drugod), selektivno jih je najti tudi $v$ literaturi (Literaturverzeichnis) cit. Musikgeschichte der Südslawen, 237-251. Večidel so bile objavljene v MZ, pa tudi v Zvuku, Arti musices in International Review of the Aesthetics and Sociology of Music, prej tudi $\mathrm{v}$ Slovenski glasbeni reviji. $\mathrm{Tu}$ in tam so bili natisnjeni posamezni prispevki muzikološkega značaja $\mathrm{v}$ periodiki splošno zgodovinskega (npr. Casopis za zgodovino in narodopisje, Kronika) in literarnega tipa. V tej zvezi naj bo omenjeno, da so bili, čeravno redko, njihovi avtorji tudi strokovnjaki z drugih znanstvenih področij, ki pa so $\mathrm{v}$ svojih raziskavah naleteli tudi na zanimive drobce iz preteklosti slovenske glasbe (npr. Smolik M., Franciscus Josephus Thallmainer 1698-1768, MZ III; Voje J., Franciscus de Pavonibus organist $v$ Dubrovniku leta 1463, MZ III; Gestrin F., Piskač Andrej iz Ljubljane - ok. leta 1472, MZ VII).

${ }^{30} \mathrm{Za}$ evidenco objav velja tudi za te prispevke to, kar je bilo receno $\mathrm{v}$ op. 29.

${ }^{31}$ Dosedanji prispevki, ki se posredno ali neposredno vežejo na vprasanja zgodovine slovenske glasbe oz. zgodovine glasbe na slovenskem prostoru, so tile: Neznani Gallusov autograf (W. Braun, MZ V), Gabriel Plautzius - dvorni kapelnik $v$ Mainzu (A. Gottron, MZ IV), Moteti Jakoba Gallusa in nauk o figurah v prvi polovici 17. stoletja (H. J. Busch, MZ V), Rex Asiae et Ponti - Poklonitveno delo Cypriana de Roreja (B. Meier, MZ VI), Prispevek $k$ odnosom Jacobusa Gallusa Handla do Prage (J. Snižkova, MZ VI). - V zv. I-XII MZ so bili objavljieni కe številni prispevki neslovenskih avtorjev $\mathrm{s}$ tematiko, ki sega $\mathrm{v}$ širok evropskı 
V obdobju, o katerem je govor, so bile razmeroma obsežne tudi raziskave v smeri novejše slovenske glasbe. Spodbudile so jih velike spremembe, ki so se pokazale $\mathrm{v}$ zadnjih desetletjih, ko se je slovensko glasbeno ustvarjanje začelo usmerjati $\mathrm{v}$ nova, za evropski glasbeni Zahod značilna gibanja. Precejšnji rezultati so znani že iz tridesetih let, po drugi vojni pa so še večji in prizadevanja $v$ nakazanem smislu še intenzivnejša. Po leg tradicionalistov in nekaterih predstavnikov slovenske glasbene moderne tridesetih let ${ }^{33}$ zdaj nastopijo še številni mlajši in mladi skladatelji.34 Zglede iščejo $\mathrm{v}$ sodobnih evropskih pojavih, $\mathrm{v}$ slovensko glasbo prinašajo najnovejša dognanja, ki jih z dosežki lastnih spoznanj š క̌irijo. To je $\mathrm{v}$ slovenskj glasbeni publicistiki in kritiki odmevalo na različne načine, kot povsod tudi tu pozitivno ali odklonilno. Razmišljanje o razvojno tako pomembnih fenomenih in njihovih nosilcih pa se ni omejilo samo na to. Novo $v$ slovenski glasbeni produkciji je zahtevalo sistema-

glasbeni prostor in je zgodovinska ali se bavi tudi $\mathrm{z}$ vprašanji drugih muzikoloških disciplin, tako npr. sociologije in estetike glasbe. Med pisci te vrste prispevkov so bili doslej npr. M. Velimirović (MZ I: Giovanni Sebenico), B. Bujić (MZ II: Cecchinijeva tretja knjiga madrigalov Amorosi concetti; MZ IV: Zadarski neumatski fragmenti $v$ Oxfordu; MZ XII: An Early Croat Translation of Rinuccini's "Euridice»), I. Supičić (MZ V: Estetika Stjepana Suleka; MZ IX: Zvok kot gradivo ali znak in smisel glasbe), $\mathrm{H}$. Stevens (MZ II: Barok in skladatelji 20. stoletja), D. Stefanović (MZ IV: Prispevek $k$ preučevanju slovanske pravoslavne glasbene kulture), C. Rihtman (MZ IV: O poreklu staroslovanskega obrednega petja na otoku Krku), H. Federhofer (MZ V: Konec glasbene parodije; MZ VII: Razmerje med posebnim in splošnim $v$ Beethovnovih klavirskih sonatah), $\mathbf{H}$. $\mathrm{H}$. Eggebrecht (MZ VIII: Musikalische Analyse - Heinrich Schütz), P. Petrobelli (MZ VIII: Note sulla poetica di Bellini), Z. Lissa (MZ IX: Poljske ljudske pesmi v priredbi Ludwiga van Beethovna), J. Andreis (MZ IV: Pozabljeni nokturno Ferda Livadića), L. Zupanovic ( $\mathrm{MZ}$ III: Iz korespondence Ivana Zajca), Z. Kucukalic (MZ X: Samospevi Petra Konjovića), S. Djuric-Klajn (MZ II: Glasbena esejistika in muzikologija pri Srbih), R. Pečman (MZ IX: Zum Begriff des Rokokostils in der Musik), W. Boetticher (MZ IX: Zum Problem der letzten Streichquartette Beethovens), K. L. Hicken (MZ X: Structure and Prolongation: Tonal and Serial Organization in the Introduction of Schoenberg's Variations for Orchestra), D. Petrović (MZ XI: Pričevanja o potovanjih po balkanskem polotoku od XV. do XVII. stoletja), A. Feil (MZ XI: Zur Genesis der Gattung Lied wie sie Franz Schubert definiert hat), J. Vysloužil (MZ XI: Antoine Reicha, ami de jeunesse de L. van Beethoven), K. Kos (MZ XI: Appariran per me le stell' in cielo von O. di Lasso und J. Skjavetić), E. Helm (MZ III: Libreto in kriza opere nekdaj in danes), M. Stëdroň (MZ IV: Leoš Janaček in avantgarda dvajsetih let; MZ X: Ugotavljanje tipičnosti nekaterih melodičnih struktur v vokalni melodiki Janačkove opere Slucaj Makropulos); J. Racek (MZ XII: Die geschichtliche Periodisierung des tschechischen Musikbarocks).

${ }^{32}$ Izšle so pri Slovenski matici (Skladatelji Gallus-Plautzius-Dolar in $n j$ hovo delo, 1963; J. Gallus, Harmoniae morales, 1966; J. Gallus, Moralia, 1968) in v seriji Slovensko glasbeno izročilo (A. T. Linhart, Dve ariji za glas in klavir, 1967; F. Gerbič, Zbori, 1967). Sem spada tudi v op. 22 omenjeni Dolarjev Miserere, ki je izšel v Zbirki Musik alter Meister, zv. 36-37, Graz 1974.

${ }_{33} \mathrm{~K}$ temu gl. Cvetko D., Histoire de la musique slovène, 1967, $292 \mathrm{ss}$. In Rijavec A., Slovene Music in the Twentieth Century, Zvuk 1967, št. 77-78.

${ }^{34} \mathrm{Gl}$. ibid. in Rijavec A., Twentieth Century Slovene Composers - Slowenische Komponisten des 20. Jahrhunderts, 1975.

${ }_{35}$ Rijavec A., Kompozicijski stavek komornih instrumentalnih del Slavka Osterca (habil. delo), 1972; Klemenčič J., Kompozicijski stavek v klavirskih skladbah Marija Kogoja (mag. delo, 1976). 
tične raziskave, ki so vodile $\mathrm{k}$ izčrpnim orisom vecjega ${ }^{35}$ in manjšega obsega, v katerih so zajete značilnosti ustvarjalnega dela starejšega ${ }^{36}$ in novejšega obdobja $\mathrm{v}$ novo usmerjene slovenske glasbe. ${ }^{37} \mathrm{Ti}$ orisi, ${ }^{38}$ iz katerih je razvidna težnja, da bi vrednotenje čimbolj ustrezalo temu, kar zanj nudi gradivo, se pravi same kompozicije, in bi se $\mathrm{v}$ kar največji meri približalo objektivnim merilom, bodo lahko $\mathrm{v}$ nadaljevanju vodili $\mathrm{v}$ snovanje celostno zajetih monografij o osrednjih osebnostih slovenske glasbene moderne.

Razen prizadevanj na področju zgodovine glasbe nasploh in posebej

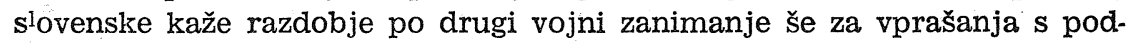
ročja akustike ${ }^{39}$ in nekaj tudi $\mathrm{v}$ smeri estetike glasbe.40

$\mathrm{V}$ širšem smislu sodijo med povojna muzikološka prizadevanja tudi slovenski prispevki $\mathrm{v}$ domačo in tujo leksikalno oziroma enciklopedicno literaturo, ${ }^{41}$ za katero se $\mathrm{v}$ večini primerov zahteva posebna sistematika. Tu so potrebe cedalje večje in je krog sodelavcev vedno širši. To velja $\mathrm{v}$ glavnem tudi za sodelovanje $\mathrm{v}$ drugih muzikoloških tiskih ${ }^{42}$ in še $\mathrm{v}$ projektih, za katere so predhodno potrebna pripravljalna dela muzikološke narave. ${ }^{43}$

Bolj kot prej se je po drugi vojni na Slovenskem razrasla tudi glasbena publicistika, $\mathrm{ki}$ ji lahko sledimo $\mathrm{v}$ razni glasbeni in literami perio-

36 $\mathrm{V}$ tej zvezi so nastali številni prispevki, med njimi: Loparnik B., Dramaturška in kompozicijska zasnova Kogojeve opere Kar hočete, MZ II; isti, prvine melodicne dikcije $v$ Kogojevih otroških pesmih, $\mathrm{MZ} \mathrm{V}$; isti, Andante za violino in klavir Marija Kogoja, MZ XI; Bedina K., K vprašanju o kompozicijskih nazori Slavka Osterca, MZ IV; Pokorn D., Slavko Osterc (Prispevek za biografijo), MZ V; Segula T., Zborovske kompozicije Slavka Osterca, MZ VI; isti, Samospevi Slavka Osterca do njegovega koncerta $v$ letu 1925, MZ VII; Klemenčič I.j Melodika v klavirskih skladbah Marija Kogoja, MZ IX; isti, Kogojeva suita za orkester "Ce se pleše, MZ XII; Rijavec A., Komorno kompozicijsko snovanje Slavka Osterca pred njegovim odhodom $v$ Prago, $\mathrm{MZ} \mathrm{V}$; isti, $K$ vprašanju tonalnosti in vertikale $v$ skladbah Slavka Osterca, MZ VI; isti, Klangliche Realisierungen im Werk von Uroš Krek, MZ XII; Leskovic R., Komorne skladbe Srecka Koporca, MZ X; Merkư P., Identiteta in otroštvo Marija Kogoj, MZ XII.

${ }^{37}$ Npr. Rijavec A., Novejši slovenski godalni kvartet, MZ IX; isti, The Stylistic Orientation of Primoz Ramovz, $\mathrm{MZ}$ X; isti, Problem forme $v$ delih Iva Petrica, MZ XI.

${ }_{38}$ Kolikor gre za manjše razprave, so te bile večidel objavljene v MZ I-XII, pa tudi drugod $\mathrm{v}$ domačem in tujem strokovnem tisku (gl. napotek $\mathrm{v}$ op. 29). Razen tu navedenih so iz virov razvidni še nekateri nadaljnji avtorji prispevkov $\checkmark$ tej smeri.

${ }^{39}$ Adlešic M., Svet zvoka in glasbe, 1964; Ravnikar B., Akustična studija drumeljce, MZ VI, 1970.

${ }^{40}$ Estetskih vprašanj se bolj ali manj dotika vsak raziskovalec $s$ pođročja zgodovine glasbe, splošne in slovenske; osrednje zanimajo V. Ukmarja. Obsežnejše objave po tej strani še niso na voljo.

4 Npr. v MGG, ME in še v drugih izdajah te vrste, kot so Grove's Dictionary of Music and Musicians, La Musica-Dizionario, Encyclopédie de la musique (ed. Fasquelle), Riemann-Musiklexikon, Dictionary of Contemporary Music. V tej zvezi je omeniti tudi sodelovanje v SBL in raznih drugih leksikonih in enciklopedijah.

42. Répertoire International de Littérature musicale; Répertoire International des Sources musicales.

${ }^{43} \mathrm{Npr}$. za glasbeni terminološki slovar, ki ga pripravlja umetnostna sekcija terminološke komisije SAZU. 
diki, precej pa se predstavlja tudi $\mathrm{s}$ samostojnimi knjižnimi izdajami.44 Deloma se posveča slovenski glasbi, ${ }^{45}$ vendar sega tudi izven nje. S težnjo za usposabljanje širokih množic za umevanje glasbe vključuje v svoj program tudi tème iz splošne zgodovine glasbe, ki veljajo za posamezna razvojna obdobja in pomembne skladatelje. 46 Način obravnavanja, ki se ga poslužujejo ti orisi, seveda ni tak, kor ga zahteva znanstveno razpravljanje. Poljuden je, namenu prilagojen.

Po drugi vojni so bili $\mathrm{v}$ raziskovanju slovenske glasbe, za katero so seveda $\mathrm{v}$ preučevanju gradiva in sklepanju upoštevani tudi specifični razvojni pogoji, ne da bi to zmanjšalo vlogo komparacije s širokim evropskim glasbenim prostorom, doseženi relativno ugodni rezultati. Načrtno delo pa zahteva še večjo koncentracijo vanj vključenih delavcev in realizacijo vseh elementov raziskovalnega procesa. To je lahko izvedljivo le $\mathrm{v}$ institutskem okviru, ki formalno obstaja, ${ }^{47}$ ne pa tudi $\mathrm{v}$ praksi in zato prizadevanja še niso tako dimenzionirana kot bi morala biti.

Slovenska muzikologija se $\mathrm{v}$ svojem razvoju srečuje $\mathrm{s}$ problemi, ki opozarjajo na doslej premalo uresničene ali sploh še neuresničene naloge. Dosežki na področju splošne zgodovine, estetike in akustike glasbe niso zadostni. Vzroke za to je treba iskati $\mathrm{v}$ pomanjkanju specializiranih znanstvenih delavcev, za estetiko glasbe tudi $\mathrm{v}$ idejno občutljivih izhodiščih za interpretiranje njene problematike. Te in one vrste razlogi pojasnjujejo tudi premajhno zanimanje za teorijo glasbene vzgoje, za sociologijo in psihologijo glasbe. Navzlic prioriteti zgodovine slovenske glasbe so omenjena področja za razvoj slovenske muzikološke misli potrebna. Zahteva jih tudi njena aktualnost $\mathrm{v}$ slovenskem znanstvenem delu kot celoti in ravno tako naloge, ki jih mora opravljati $v$ širšem evropskem in svetovnem okviru.

\section{SUMMARY}

First musicological efforts in the broad meaning of the word appear in Slovenia towards the end of the 19th and at the beginning of the 20th century. However, neither at that time nor between the two wars were they systematic. They unfolded along the lines of musical historiography, ethnology and aesthetics bearing certain, if not extensive, results. Still, before World War II, musical journalism and criticism were quite developed, due mostly to extensive compositional results which were gaining European horizons.

After World War II, the conditions for the development of Slovene musicology improved significantly. This discipline found, as a university subject, its lebensraum at first within the Academy of Music and later in the Philosophical Faculty of the University of Ljubljana; the Musicological Annual began to be published, stimulated by other forms and results of research, master's and doctor's theses, habilitation works, as well as by increased possibilities for publishing not only.

44 Te so obsežene predvsem $\mathrm{v}$ zbirki Umetnost in kultura, ki je zanjo najprej skrbel Prosvetni servis in zatem Delavska enotnost, oboje v Ljubljani.

${ }_{45}$ Prikazana so posamezna razvojna obdobja slovenske glasbe in predstavljenl nekateri skladatelji iz neposredne preteklosti.

46 Dosedanji orisi obsegajo zgodnjo, pozno in novo romantiko ter sodolbno glasbo, pa še nekaj osebnosti iz pretekle evropske glasbe.

47 Muzikološki institut SAZU je bil $s$ sklepom letne skupščine te institucije osnovan leta 1972, zaradi tehnicnih razlogov pa doslej z delom še ni mogel zaceti. 
within planned projects but also by growing musicological activites in the national and international musicological sphere.

During this period, Slovene musicology has directed its research mostly to the history of Slovene music, old and new. A number of monographs dealing with smaller or larger sections of the Slovene musical past and present were written, as well as books on individual composers, numerous articles, and also a number of works, written by past Slovene composers, have been edited.

Apart from the efforts in the field of musical history, especially Slovene, the period in question reflects an interest in musical acoustics and aesthetics.

Numerous contributions to national and international, lexical or rather encyclopaedic literature should also be mentioned, as well as participation in other prints and projects, which need extensive musicological praparatory work.

More then ever before, we witness the effloressence of musical journalism, in musical as well as literary magazins, and in the form of independent publications. Although dedicating itself mostly to Slovene music, musical journalisin has dealt also with periods within the general musical history and individual composers, which are interesting in the European setting.

Results obtained since World War II indicate that in the contributions of Slovene musicological efforts full attention has been paid to the specific conditions of development and to comparative study within the broader European context. What has been achieved deserves positive marks, however with the additional remark that a greater concentration of musicologists doing research should be striven for. The latter is possible only within an institutional framework which formally exists (The Musicological Institute of the Slovene Academy of Arts and Sciences, founded 1972) but, because of the lack of technical conditions, has not been in the position to accept concrete tasks.

Postwar Slovene musicology has of course various problems to cope with, and these indicate how much work still remains to be done - in the direction of greater efforts in the field of general musical history as well as sociology and aesthetics, two musicological disciplines, which, though important for the development of Slovene musicological thought, have been hitherto hardly present in Slovenia. 